\title{
ИССЛЕДОВАНИЕ ВЗАИМОСВЯЗЕЙ МЕЖДУ ХИМИЧЕСКИМ СОСТАВОМ ВОД И ДОННЫХ ОТЛОЖЕНИЙ РЕК СИБИРИ
}

\author{
Савичев Олег Геннадьевич, \\ oSavichev@mail.ru \\ Национальный исследовательский Томский политехнический университет, \\ Россия, 634050, г. Томск, пр. Ленина, 30.
}

\begin{abstract}
Актуальность. Понимание механизма и количественная оценка взаимодействия между речными водами и веществом речных наносов, донных отложений и берегов представляет собой методологическую основу планирования мероприятий по рекультивации нарушенных водных объектов, экологического мониторинга и гидрогеохимических поисков полезных ископаемых. Цель работы: количественное описание взаимосвязей между химическим составом речных вод и донных отложений. Методы исследования: статистические методы, математическое моделирование гидрогеохимических процессов. Результаты и выводы. Рассмотрена математическая модель взаимосвязей концентраций $\mathrm{Fe}, \mathrm{Cu}, \mathrm{Pb}, \mathrm{Zn}$, As водах и донных отложениях рек Омутная (речная система Омутная-Киргизка-Томь-Обь), Ильбокич, Боткич, Верхняя и Нижняя Немба, Инганба (притоки реки Чадобец; система Чадобец-Ангара-Енисей) и Актру (система Актру-Чуя-Катунь-Обь). Предложен алгоритм определения параметров этой модели, включающий регрессионный анализ и использование методов оптимизации. Показано, что связи между химическим составом речных вод и донных отложений существенно не линейны и зависят от абсолютных и относительных характеристик интенсивности водообмена, заболоченности водосборных территорий и рН речных вод. Установлено, что абсолютное и относительное приращение концентраций в речных водах обычно меньше, чем соответствующее приращение концентраций в донных отложениях. В то же время иногда отмечаемые высокие концентрации Fе и повышенные содержания некоторых микроэлементов могут быть связаны не только с наличием природных геохимических аномалий в донных отложениях или загрязнением водного объекта, но и с определенными сочетаниями природных условий, например, с приближением фактической сорбции к максимально возможным значениям.
\end{abstract}

Ключевые слова:

Донные отложения, речные воды, химический состав, математическая модель, таежная зона Сибири.

\section{Введение}

Химический состав речных вод формируется в результате комплекса различных процессов, включая взаимодействие между речными водами и веществом речных наносов, донных отложений и берегов. Понимание механизма и количественная оценка таких взаимодействий представляет собой методологическую основу одновременно и гидрогеохимических поисков полезных ископаемых, и планирования рекультивации нарушенных водных объектов, и геоэкологического мониторинга $[1,2]$. По этой причине их изучению посвящено огромное количество работ, среди которых следует отметить работы [3, 4], в которых предпринята попытка теоретически обосновать взаимосвязи между водным, твердым и химическим стоком и приведено наиболее полное обобщение исследований донных отложений. Тем не менее целый ряд вопросов остался недостаточно раскрытым, в результате чего до сих пор не разработаны способы расчета сбросов загрязняющих веществ в водные объекты с учетом геохимического состояния донных отложений, а в ряде случаев эффективность гидрогеохимических поисков остается недостаточно высокой [5-8].

С учетом этого был выполнен анализ взаимосвязей между геохимическими показателями речных вод и донных отложений на основе модели, учитывающей процессы сорбции, растворения, осаждения, а также влияние потока на их скорость и полноту. Целью анализа является количественное описание механизма взаимодействия речных вод и донных отложений, пригодное для оптимизации методик гидрогеохимических поисков полезных ископаемых и геоэкологического мониторинга. Исходной информацией послужили данные о химическом составе вод и донных отложений рек Омутная, Ильбокич, Боткич, Верхняя и Нижняя Немба, Инганба, Актру.

Река Омутная является элементом речной системы Олутная-Киргизка-Толь-Обь (Томская область, Российская Федерация). Водосбор расположен в районе Туганского циркон-ильменитового месторождения и проявления полиметаллической и благороднометалльной минерализации $[9,10])$. Водовмещающие отложения палеоген-четвертичного возраста [11]. Полевые работы проведены 23.06.2018 г.

Реки Ильбокич, Боткич, Верхняя и Нижняя Немба, Инганба являются притоками реки Чадобец - элемента системы Чадобеи-Ангара-Енисей (Красноярский край, Российская Федерация). Водовмещающие отложения палеозойского, мезозойского и кайнозойского возрастов; палеозойские отложения прорваны основными породами формации сибирских траппов [12]. Полевые работы проведены 13-17.08.2008 г.

Река Актру - элемент речной системы $A \kappa$ тру-Чуя-Катунь-Обь (республика Алтай, Российская Федерация). Водосбор сложен гранитоидами Актуринского массива пермо-триасового возраста. В его пределах выявлены участки, перспективные на проявления золота, цинка, свинца и приуроченные к Актуринской магмо-рудно-мета- 
соматической системе [13]. Полевые работы выполнены В.В. Паромовым 18-20.07.2013 г.

Выбор объектов обусловлен, с одной стороны, приуроченностью к участкам фактического или потенциально возможного обнаружения рудопроявлений в таежной зоне Северной Азии [9], а с другой стороны - наличием измерений расходов воды, скоростей течения, глубины потока и материалов одновременного изучения химического состава вод и донных отложений с использованием современных и сопоставимых (или одних и тех же) методов исследования. В рассматриваемом случае использовались данные, полученные в лабораториях Tомского политехнического университета (ТПУ) и 000 «Плазма» (г. Томск) с использованием методов: $\mathrm{pH}$ - потенциометрический; $\mathrm{Ca}^{2+}, \mathrm{Mg}^{2+}, \mathrm{HCO}_{3}^{-}$, $\mathrm{CO}_{3}{ }^{2-}, \mathrm{CO}_{2}, \mathrm{Cl}^{-}$, перманганатная (PO) и бихроматная (ВО) окисляемость - титриметрический; $\mathrm{SO}_{4}{ }^{2-}-$ турбидиметрический; $\mathrm{Na}^{+}, \mathrm{K}^{+}-$ионная хроматография; $\mathrm{Si}, \mathrm{NH}_{4}^{+}, \mathrm{NO}_{2}^{-}, \mathrm{NO}_{3}^{-}, \mathrm{PO}_{4}^{3-}-$ фотометрический; Fе и микроэлементы - спектрометрия с индуктивно-связанной плазмой и извлечением кислоторастворимых форм элементов. Подробная информация об указанных объектах и используемых методах определения приведена в $[11,12]$.

Особенностью работы является достижение поставленной цели путем разработки и апробации математической модели формирования содержаний $\mathrm{Fe}, \mathrm{Cu}, \mathrm{Zn}, \mathrm{Pb}, \mathrm{As}$, что определило структуру рассматриваемой работы. Химические элементы выбраны с учетом попытки повысить эффективность водоохранных мероприятий и работ по выявлению участков водных объектов с повышенными относительно нормативов концентрациями (в Сибири практически повсеместно - Fе, очень часто $\mathrm{Cu}, \mathrm{Zn}$, в ряде случаев, включая антропогенно измененные территории - Pb и As [2, 14-16]).

\section{Математическая модель взаимосвязей между химическим составом речных вод и донных отложений}

Любая модель - всегда набор определенных допущений и упрощений, который более или менее адекватно описывает исследуемый фрагмент реальности. Нами (с учетом подходов $[6,7,17-19]$ к совместному описанию сорбции, растворения и осаждения) был использован следующий набор уравнений:

$$
\begin{gathered}
\frac{d C}{d t}=\varphi_{d s}+\varphi_{s r b}=\varphi_{0}-k_{r} C, \\
\varphi_{d s}=k_{p 0}\left(k_{p 1} C_{p}-C\right) \approx k_{p 0}\left(k_{g} M_{a Q}^{b_{1}} C_{g}-C\right), \\
\varphi_{s r b}=k_{s}\left(S-k_{c} C\right) \approx k_{s}\left(S-k_{m}\left(S_{m}-S\right) C\right), \\
k_{r}=k_{p 0}+k_{s} k_{m}\left(S_{m}-S\right),
\end{gathered}
$$

где $t$ - координата времени; $\varphi_{d s}$ и $\varphi_{s r b}-$ функции, описывающие процессы растворения-осаждения (2) и сорбции-десорбции (3), соответственно; $\varphi_{0}-$ функция, слабо зависящая от времени и расхода воды $Q$ в момент времени $t ; C$ и $S$ - концентрация исследуемого вещества в речных водах и донных отложениях, соответственно; $C_{p}-$ концентрация вещества в речных водах, соответствующая локальному равновесию в системе вода-порода и аппроксимируемая, согласно [20], средним геометрическим $C_{g}$ с учетом поправки на отклонение от равновесия, связанное с пространственными изменениями среднемноголетнего модуля водного стока $M_{a Q} ; S_{m}$ - максимальная сорбционная способность донных отложений; $k_{p 0}, k_{p 1}, k_{g}, b_{1}, k_{s}, k_{m}$ - эмпирические коэффициенты.

При $\frac{d C}{d t}=0$ концентрации веществ в речных водах и донных отложениях определяются уравнениями:

$$
\begin{gathered}
C_{e}=\frac{k_{s} S+k_{p 0} k_{p 1} C_{p}}{k_{r}}=\frac{S+\frac{k_{p 0}}{k_{s}} k_{p 1} C_{p}}{\frac{k_{p 0}}{k_{s}}+k_{m}\left(S_{m}-S\right)}, \\
S_{e}=\frac{k_{s} k_{m} S_{m} C+k_{p 0} C-k_{p 0} k_{p 1} C_{p}}{k_{s}+k_{s} k_{m} C}= \\
=\frac{k_{m} S_{m} C+\frac{k_{p 0}}{k_{s}}\left(C-k_{p 1} C_{p}\right)}{1+k_{m} C} .
\end{gathered}
$$

В общем случае при допущениях

$$
\frac{d C}{d t}=\frac{d C}{d Q} \frac{d Q}{d t} \approx \frac{d C}{d Q} \lambda Q \text { и } \frac{k_{r}}{\lambda} \approx \text { const }
$$

( $\lambda$ - удельная скорость изменения расхода воды) в качестве решения (1) рассматривается как отклонение некоторого устойчивого состояния при среднемноголетнем расходе воды $Q_{a}$ :

$$
C=C_{e}+\left(C_{0}-C_{e}\right)\left(\frac{Q}{Q_{a}}\right)^{-\frac{k_{r}}{\lambda}},
$$

где $C_{0}$ - концентрация вещества в начальный момент времени, принимаемая, с учетом [20, 21], как среднее геометрическое $C_{g}$.

\section{Методика исследования}

Модель (4)-(7) содержит значительное количество неизвестных параметров, измерить которые сложно или невозможно. С учетом этого использовались методы оптимизации (метод общего понижающего градиента; реализация в пакете MS Excel) c минимизацией функции:

$$
N S^{*}=\sqrt{1-N S}=\frac{1}{\sigma_{o}} \sqrt{\frac{\sum\left(y_{o}-y_{s}\right)^{2}}{N-1}},
$$

где $N S$ - критерий Нэша-Сатклифа [22]; $y_{0}$ и $y_{s}-$ измеренные и вычисленные значения исследуемой величины $y$; $\sigma_{0}$ - среднее квадратическое отклонение измеренных значений $y_{0} ; N$ - объем выборки. Зависимость принимается удовлетворительной при $N S<0,8(N S>0,36)$. 
Для более эффективного поиска минимума функции (8) предложен следующий алгоритм определения параметров модели (4)-(7):

1) в первом приближении подбираются значения $k_{m}$ и $S_{m}$ в уравнении Лэнгмюра при минимуме (8):

$$
S=\frac{k_{m} S_{m} C}{1+k_{m} C}
$$

2) из уравнения (9) обратным расчетом по известным значениям $S, C, k_{m}$ находится величина $S_{m}$, для которой с помощью метода наименьших квадратов подбирается уравнение связи с гидрологическими и геохимическими показателями $y_{F, j}(j=1, \ldots, m)$ в виде:

$$
\ln S_{m}=\ln S_{m, 0}+\sum\left(b_{F, j} \ln y_{F, j}\right),
$$

где коэффициенты $\ln S_{m, 0}$ и $b_{F m j}$ определяются при условии превышения удвоенной погрешности их определения и $N S>0,36$;

3) подбираются значения $k_{g}, b_{1}$ и (в первом приближении) $k_{r} / \lambda$ в уравнении (7) при условии, что $C_{0}=C_{g}$ и $C_{e} \approx k_{g} M_{Q}^{b_{1}} C_{g}$;

4) для известных значений $S_{m, 0}, b_{F m j}, k_{g}, b_{1}$ подбираются значения $k_{m}, k_{p 0} / k_{s}$; и $\Delta S_{m}\left(S_{m} *=S_{m, 0}+\Delta S_{m}\right)$;

$5)$ для известных значений $S_{m, 0}, \Delta S_{m}, b_{F m j}, k_{g}, b_{1}, k_{m}$, $k_{p 0} / k_{s}$ подбираются значения $k_{r} / \lambda$.

В качестве аргументов зависимости вида (10) использовались расход воды $Q\left(\mathrm{~m}^{3} / \mathrm{c}\right)$, модуль водного стока $M_{Q}($ л/(c·км²)), коэффициент шероховатости $n_{r}$ (в формуле Шези-Маннинга), предельный диаметр неподвижной фракции донных отложений $d_{s b, l i m}=0,012 \frac{v^{3}}{\sqrt{h}}(v-$ средняя скорость течения, м/c; $h$ - средняя глубина потока, м; $d_{s b, l i m}$ в м [23]), pH, бихроматная и перманганатная окисляемость, концентрации макрокомпонентов, фосфатов, железа и кремния, а также коэффициенты вариации среднегодовых расходов воды $\operatorname{Cv}\left(Q_{y}\right)_{1}$ и среднемесячных расходов в среднем за многолетний период $\operatorname{Cv}\left(Q_{m}\right)_{2}$ (коэффициенты вариации приняты для рек Ильбокич, Боткич, Верхняя и Нижняя Немба, Инганба - по реке-аналогу Чадобец, для реки Омутная - по реке-аналогу Киригизке; для Актру - по данным гидрометрических наблюдений непосредственно на этом водотоке).

После определения параметров модели (4)-(7) выполнялось моделирование изменений концентраций $\mathrm{Fe}, \mathrm{Cu}, \mathrm{Zn}, \mathrm{Pb}, \mathrm{As}$ для абстрактной реки с площадью водосбора $F_{b}=3000 \mathrm{kм}^{2}$ (нижний диапазон категории «средняя река» в равнинных условиях) и диаметром донных отложений $d_{s b, l i m}=0,001$ м. Среднемноголетние значения расхода воды $Q_{a}$ (среднее арифметическое), $\sigma_{a}$ (среднее квадратическое отклонение), среднегеометрические значения $\mathrm{pH}_{g}, \mathrm{PO}_{g}, \mathrm{BO}_{g}, C_{g}\left(\mathrm{HCO}_{3}^{-}\right), C_{g}\left(\mathrm{NH}_{4}^{+}\right)$, $C_{g}(\mathrm{P})$ определялись по эмпирическим зависимостям (11)-(18), полученным методом наименьших квадратов для 60 средних рек бассейнов Оби, Енисея и Лены (по данным Росгидромета):

$$
Q_{a}=(0,007600 \pm 0,0000384) F_{b}, \quad N S=0,87,
$$

$$
\begin{gathered}
\sigma_{a}=(0,001354 \pm 0,000050) F_{b}, N S=0,92, \\
\ln C_{g}\left(\mathrm{HCO}_{3}^{-}\right)=(5,236 \pm 0,144)- \\
-(0,497 \pm 0,069) M_{a Q}, N S=0,47, \\
\mathrm{pH}_{g}=(5,911 \pm 0,229)+ \\
+(0,312 \pm 0,052) \ln C_{g}\left(\mathrm{HCO}_{3}^{-}\right), N S=0,41, \\
\mathrm{BO}_{g}=(21,230 \pm 5,219)+(0,714 \pm 0,169) f_{s w}- \\
-(0,595 \pm 0,247) M_{a Q}, N S=0,58, \\
\mathrm{PO}_{g}=(4,511 \pm 1,344)+(0,414 \pm 0,056) f_{s w}, \\
N S=0,61, \\
C_{g}\left(\mathrm{NH}_{4}^{+}\right)=(25,020 \pm 2,599) \mathrm{BO}_{g} \cdot 10^{-3}, N S=0,64, \\
C_{g}(\mathrm{P})=(1,327 \pm 0,158) \mathrm{BO}_{g} \cdot 10^{-3}, N S=0,36,
\end{gathered}
$$

где $F_{b}$ - площадь водосбора в км²; $f_{s w}$ - заболоченность водосбора в \% от его площади; среднемноголетний расход воды $Q_{a}$ и его среднее квадратическое отклонение $\sigma_{a}-$ в $^{3} / \mathrm{c} ; M_{a Q}-$ среднемноголетний модуль водного стока в л/(c·км²); средние геометрические значения $\mathrm{PO}$ и ВО - в мгО/ $/ \mathrm{дm}^{3} ; \mathrm{pH}-$ в единицах $\mathrm{pH} 4$ среднегеометрические значения концентраций $\mathrm{HCO}_{3}^{-}, \mathrm{NH}_{4}^{+}$, фосфора фосфатов (P) в мг $/$ дм $^{3}$. Соотношение $Q / Q_{a}$ принималось для расчетного значения коэффициента вариации $C v=\sigma_{a} / Q_{a}$ при условии соответствия эмпирической кривой обеспеченностей распределению Крицкого-Менкеля, соотношении коэффициентов асимметрии и вариации $C s=2 C v$ и для обеспеченностей расхода воды $1,10,50,90,99 \%$ (соответственно, $\left.Q / Q_{a}: 1,46 ; 1,23 ; 0,99 ; 0,78 ; 0,64\right)$.

Средние геометрические концентрации $\mathrm{Fe}, \mathrm{Cu}$, $\mathrm{Zn}, \mathrm{Pb}, \mathrm{As}$, которые использовались при определении параметров уравнений (1)-(7), рассчитаны по данным наблюдений в соответствующем водосборе (для р. Омутной - за период 1998-2018 гг., для р. Актру - по данным о реках Актру и Тюте за период 1997-2014 гг., в случае рек Ильбокич, Боткич, Верхняя и Нижняя Немба, Инганба - данные за 2008-2009 гг. по всем указанным водотокам). При моделировании были заданы постоянные значения $C_{g}: \mathrm{Fe}-0,9$ мг $/$ дм $^{3} ; \mathrm{Cu}, \mathrm{Zn}, \mathrm{Pb}, \mathrm{As}-0,9$ мкг $/$ дм $^{3}$.

В процессе моделирования для заданной обеспеченности расхода воды $P$ и $F_{b}=3000 \mathrm{kм}^{2}$ использовался 21 сценарий с комбинацией различающихся исходных параметров: 1) $f_{s w}=50 \%, M_{a Q}=7,6 \pi /\left(\mathrm{c} \cdot \mathrm{\kappa M}^{2}\right)$, $\mathrm{pH}=4,5,6,7,8,9$ (варианты V1-V6, соответственно); 2) $f_{s w}=5 \%, M_{a Q}=7,6$ л/(с· $\left.\mathrm{KM}^{2}\right), \mathrm{pH}=4,5,6,7,8,9$ (варианты V7-V12); 3) $f_{s w}=5 \%, M_{a Q}=15,2$ л/(с.км²), $\mathrm{pH}=4,5,6,7,8,9$ (варианты V13-V18). Дополнительно использовались варианты V19-V21, в которых значение $\mathrm{pH}$ определялось по зависимостям $(13,14)$ при условиях, указанных в сценариях 1,2 , 3. Всего - 105 сценариев (21 сценарий для каждого модульного коэффициента $Q / Q_{a}$ ). 


\section{Результаты исследования и их обсуждение}

Корреляционный анализ показал, что для рек Омутная, Ильбокич, Боткич, Верхняя Немба, Нижняя Немба, Инганба, Актру значимая корреляционная связь (при уровне значимости 5 \%) между концентрациями в донных отложениях и речных водах характерна только для As (причем обратная), а связь с другими компонентами химического состава речных вод выявлена в основном только для $\mathrm{Fe}$ и $\mathrm{Cu}$ (табл. 1). Однако подбор параметров модели (4)-(7) показал, что такие связи, безусловно, имеются (табл. 2), но они существенно нелинейны и сильно меняются в зависимости от водного стока, $\mathrm{pH}$ речных вод и заболоченности водосбора (табл. 3).

таблица 1. Статистически значилые* коэффициенты корреля иии между кониентрацияли $\mathrm{Fe}, \mathrm{Cu}, \mathrm{Zn}, \mathrm{Pb}, \mathrm{As}$ в дон ных отложениях $(S)$, среднелноголетним модулел водного стока $M_{a Q}$, коэффициентами вариации сред негодовых $\left(\mathrm{Cv}\left(Q_{y}\right)_{1}\right)$ и среднемесячных $\left(\mathrm{Cv}\left(Q_{m}\right)_{2}\right)$ рас ходов воды, измеренных расходов воды Q, pH и геохи мических показателей речной воды

Table 1. Statistically significant* factors of correlation between concentration of $\mathrm{Fe}, \mathrm{Cu}, \mathrm{Zn}, \mathrm{Pb}$, As in bottom sediments $(S)$, mean long-term module of water flow $M_{a Q}$, factors of a variation of mid-annual $\left(C v\left(Q_{y}\right)_{1}\right)$ and monthly $\left(\mathrm{Cv}\left(\mathrm{Q}_{\mathrm{m}}\right)_{2}\right)$ discharges, measured discharges $\mathrm{Q}, \mathrm{pH}$ and geochemical parameters of river water

\begin{tabular}{|c|c|c|c|c|c|}
\hline Показатель/Parameter & $S(\mathrm{Fe})$ & $S(\mathrm{Cu})$ & $S(\mathrm{Zn})$ & $S(\mathrm{~Pb})$ & $S(\mathrm{As})$ \\
\hline$M_{a Q}$ & $-0,70$ & $-0,64$ & - & - & - \\
\hline $\operatorname{Cv}\left(Q_{y}\right)_{1}$ & 0,48 & 0,43 & 0,49 & 0,46 & - \\
\hline $\operatorname{Cv}\left(Q_{m}\right)_{2}$ & 0,81 & 0,77 & - & - & - \\
\hline$Q$ & $-0,65$ & $-0,63$ & - & - & - \\
\hline pH речной воды/pH of river water & $-0,74$ & $-0,77$ & - & - & - \\
\hline \multicolumn{6}{|c|}{$\begin{array}{c}\text { Геохимические показатели речной воды } \\
\text { Geochemical parameters of river water }\end{array}$} \\
\hline $\begin{array}{l}\text { Сумма главных ионов } \\
\text { Sum of main ions }\end{array}$ & 0,50 & 0,66 & - & - & - \\
\hline $\mathrm{Ca}^{2+}$ & 0,42 & 0,53 & - & - & $-0,43$ \\
\hline $\mathrm{Mg}^{2+}$ & 0,61 & 0,65 & - & - & - \\
\hline $\mathrm{HCO}_{3}^{-}$ & 0,54 & 0,77 & - & - & - \\
\hline $\mathrm{SO}_{4}{ }^{2-}$ & $-0,60$ & $-0,57$ & - & - & - \\
\hline $\mathrm{NH}_{4}^{+}$ & 0,74 & 0,48 & - & - & - \\
\hline As & - & - & 0,66 & 0,66 & $-0,46$ \\
\hline $\mathrm{Si}$ & 0,79 & \begin{tabular}{|l|}
0,69 \\
\end{tabular} & - & - & - \\
\hline $\begin{array}{c}\text { Перманганатная окисляемость } \\
\text { Permanganate oxidability }\end{array}$ & 0,45 & - & - & 0,43 & - \\
\hline $\begin{array}{l}\text { Бихроматная окисляемость } \\
\text { Bichromate oxidability }\end{array}$ & 0,63 & - & - & - & - \\
\hline
\end{tabular}

Примечание: * коэффициент корреляиии г принилается значимым при условии $|r| \geq 2 \frac{1-r^{2}}{\sqrt{N-1}}$, әде $N$ - объем выборки.

Note: * correlation coefficient $r$ is accepted as significant for condition $|r| \geq 2 \frac{1-r^{2}}{\sqrt{N-1}}$, where $N$ is sample size.

Зависимость концентраций веществ в донных отложениях от расходов воды и модулей водного стока в целом обратная $(\mathrm{Fe}, \mathrm{Cu})$, что аналогично связи гидрологических характеристик с суммарным содержанием растворенных веществ в речных водах $[1,24]$. Несколько неожиданный, но вполне объяснимый результат - статистически значимые коэффициенты корреляции с коэффициентами вариации среднегодовых и среднемесячных расходов воды (табл. 1). Данный факт хорошо согласуется с концепцией маргинальных фильтров, предложенной А.П. Лисицыным [25], и свидетельствует о более благоприятных условиях аккумуляции веществ в донных отложениях рек с наибольшей изменчивостью водного и, соответственно, твердого стока.

Максимальная сорбционная способность донных отложений $S_{m}$ во многих случаях обратно пропорциональна величине $\mathrm{pH}$ речных вод, с увеличением которой может усиливаться выпадение из раствора малорастворимых гидроксидов, карбонатов и гуматов исследуемых и ряда других химических элементов одновременно и/или с последующими обменными реакциями [26-31]. Эти процессы, в свою очередь, зависят от условий накопления и выноса продуктов взаимодействия речных вод с наносами и донными отложениями [7, 32-34], причем определенную роль играет диаметр частиц донных отложений как характеристика площади их взаимодействия с речными водами $[35,36]$. Однако статистически значимую связь с величиной $d_{s b, l i m}$ удалось установить только для As (табл. 2), а также для $\mathrm{Zn}, \mathrm{Pb}, \mathrm{Cu}$ в р. Актру. Возможно, это объясняется существенными различиями условий формирования твердого стока исследуемых рек, а также неучтенным влиянием термического режима водных объектов на формы миграции химических элементов [37] и, соответственно, распределение между фракциями донных отложений с разной подвижностью.

Коэффициенты регрессии для величин $\left(\operatorname{Cv}\left(Q_{y}\right)_{1}\right)$ и $\left(\operatorname{Cv}\left(Q_{m}\right)_{2}\right)$ по модулю были несколько меньше удвоенной погрешности их определения и в расчетах не использовались. К прочим факторам формирования $S_{m}$ относятся: содержание органических веществ по бихроматной и перманганатной окисляемости (соответственно, трудно- и относительно легко окисляемые вещества), продукты его трансформации $\left(\mathrm{NH}_{4}^{+}\right.$, фосфаты по Р) и ион $\mathrm{HCO}_{3}{ }^{-}$. Связь микроэлементов с железом в виде компонента уравнения (10) не была выявлена и не использовалась при моделировании, но, как показали дополнительные расчеты, использование функции $C(\mathrm{Fe})^{b(\mathrm{Fe})}$ с подбором $b(\mathrm{Fe})$ методами оптимизации позволяет несколько снизить итоговую оценку $N S *$ для модели (4)-(7).

Величина $S_{m}$ - важный, но не ключевой фактор формирования химического состав речных вод и донных отложений. Ключевым фактором, судя по полученным данным моделирования (табл. 3), является соотношение $S_{m}$ и $S$ при заданных значениях $Q / Q_{a}, k_{r} / \lambda, k_{m}, k_{p 0} / k_{s}$. В общих чертах при увеличении концентраций $\mathrm{Cu}, \mathrm{As}$ и $\mathrm{Fe}$ в донных отложениях расчетные концентрации указанных элементов в речных водах возрастают в периоды с пониженной водностью (относительно нормы водно- 
Таблица 2. Параметры модели (4)-(7)

Table 2. $\quad$ Parameters of model (4)-(7)

\begin{tabular}{|c|c|c|c|c|c|}
\hline \multirow{2}{*}{$\begin{array}{c}\text { Параметр (уравнение) } \\
\text { Parameter (equation) }\end{array}$} & \multicolumn{5}{|c|}{ Исследуемый химический элемент/Researched chemical element } \\
\hline & $\mathrm{Fe}$ & $\mathrm{Cu}$ & $\mathrm{Zn}$ & $\mathrm{Pb}$ & As \\
\hline $\ln S_{m, 0}(10)$ & $15,220 \pm 1,365$ & $22,904 \pm 4,008$ & $4,105 \pm 0,445$ & $1,923 \pm 0,199$ & $34,816 \pm 7,982$ \\
\hline$b(\mathrm{pH})(10)$ & $-0,555 \pm 0,162$ & $-9,306 \pm 1,922$ & - & - & $-12,622 \pm 3,283$ \\
\hline$b(\mathrm{PO})(10)$ & - & - & - & $0,401 \pm 0,131$ & - \\
\hline$b(\mathrm{BO})(10)$ & $0,159 \pm 0,054$ & - & - & - & - \\
\hline$b(\mathrm{P})(10)$ & $0,155 \pm 0,045$ & - & $-0,344 \pm 0,108$ & - & - \\
\hline$b\left(\mathrm{NH}_{4}^{+}\right)(10)$ & - & - & $0,454 \pm 0,180$ & - & - \\
\hline$b\left(\mathrm{HCO}_{3}{ }^{-}\right)(10)$ & - & - & - & - & $-1,661 \pm 0,363$ \\
\hline$b\left(d_{s b, l i m}\right)(10)$ & - & - & - & - & $0,094 \pm 0,043$ \\
\hline$N S$ (8) для ур. (10)/for eq. (10) & 0,887 & 0,610 & 0,478 & 0,383 & 0,688 \\
\hline$\Delta S_{m}$ & $-151,768$ & 2,542 & $-5,353$ & 14,690 & 2,033 \\
\hline$k_{p 0} / k_{s}(5,6)$ & $-49850,164$ & $-17796,978$ & $-846,666$ & 10991,803 & $-301909,928$ \\
\hline$k_{m}(5,6)$ & 0,054 & 196800,425 & 2191,518 & 175301,896 & 533640,649 \\
\hline$k_{g}(2)$ & 2,423 & 0,846 & 14,656 & 27,095 & 1,738 \\
\hline$b_{1}(2)$ & $-0,291$ & 0,038 & $-1,146$ & $-2,007$ & $-0,300$ \\
\hline$-k_{r} / \lambda(7)$ & $-0,402$ & $-0,275$ & 0,757 & 1,008 & $-0,065$ \\
\hline$N S(8)$ для ур. (7) for eq. (10) & 0,514 & 0,412 & 0,562 & 0,817 & 0,965 \\
\hline
\end{tabular}
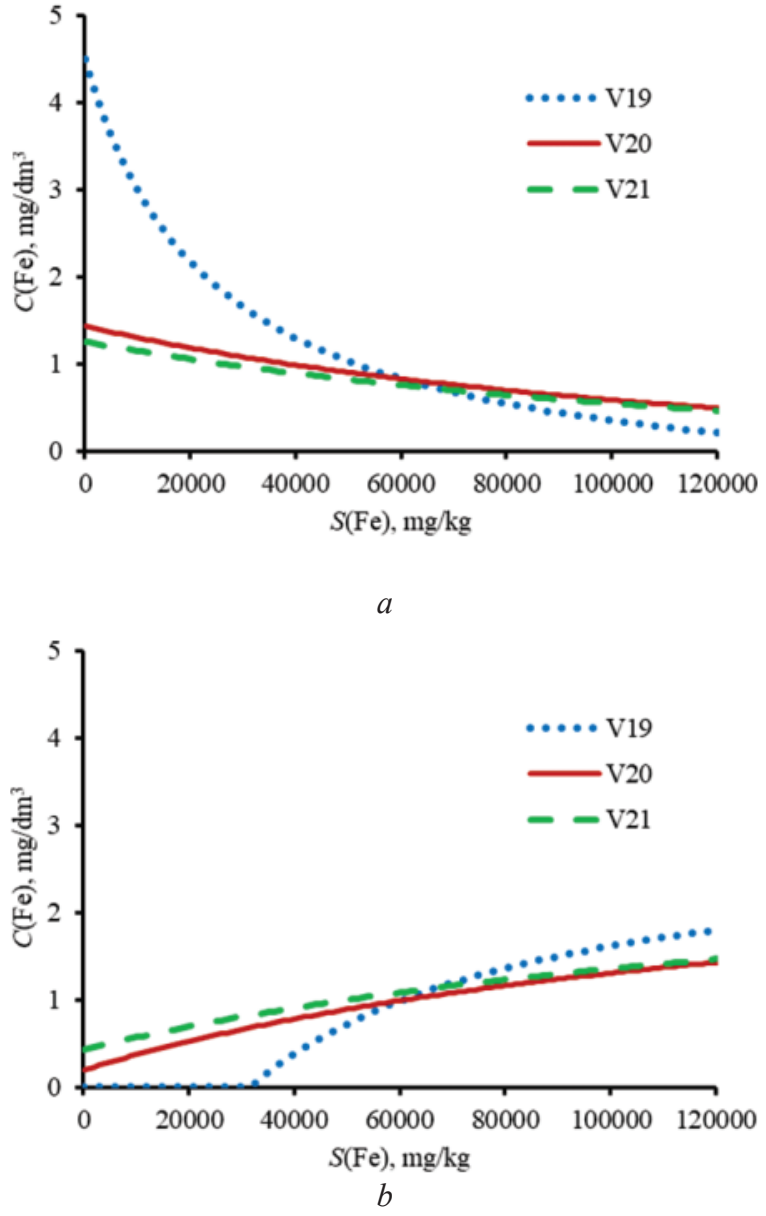

Puc. 1. Расчетные соотношения концентраций Fе в речных во дах (C) и донных отложениях (S) для сиенариев V19, V20, V21 (табл. 3) при коэффициенте водного стока $Q / Q_{a}=1,23(a) u Q / Q_{a}=0,78(b)$

Fig. 1. Simulated ratio of Fe concentration in river waters $(C)$ and bottom sediments $(S)$ for scripts V19, V20, V21 (table 3), factor of water flow $Q / Q_{a}=1,23(a)$ and $Q / Q_{a}=0,78(b)$ го стока) и снижаются в периоды с повышенной водностью (рис. 1), причем возможны такие условия, при которых будут наблюдаться резкие колебания концентраций в речных водах и донных отложениях (рис. 2, 3). Обратная картина характерна для $\mathrm{Zn}$ и $\mathrm{Pb}$ (более высокий уровень содержания возможен при более высокой водности).

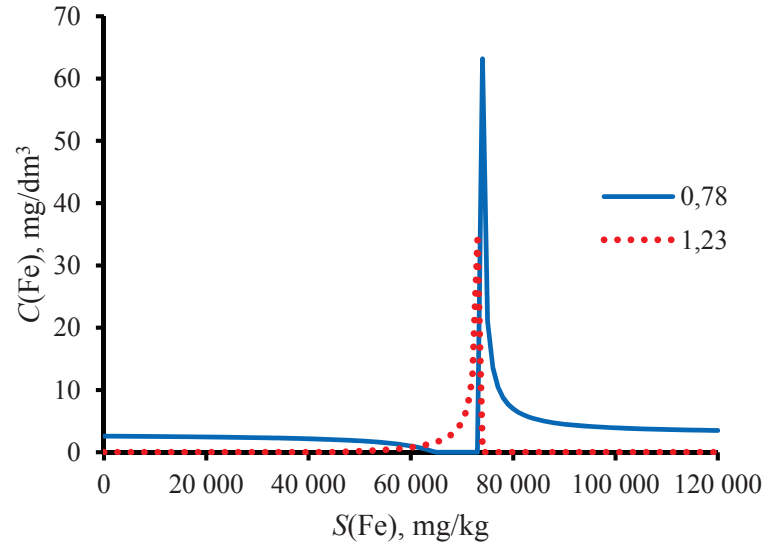

Puc. 2. Расчетные соотношения кониентраций Fе в водах (C) u донных отложениях $(S)$ реки с заболоченностью водосбоpa $f_{\text {sw }}=50 \%$ и pH=6,0 (сиенарий V3, табл. 3) при коэффиииенте водного стока $Q / Q_{a} 0,78$ и 1,23

Fig. 2. Simulated ratio of Fe concentration in waters (C) and bottom sediments $(S)$ of the river with basin marshiness $f_{s w}=50 \%$ and $p H=6,0$ (script V3, table 3), factor of water flow $Q / Q_{a} 0,78$ and 1,23

Величина $S_{m}$ - важный, но не ключевой фактор формирования химического состав речных вод и донных отложений. Ключевым фактором, судя по полученным данным моделирования (табл. 3), является соотношение $S_{m}$ и $S$ при заданных значениях $Q / Q_{a}, k_{r} / \lambda, k_{m}, k_{p 0} / k_{s}$. В общих чертах при увеличении концентраций $\mathrm{Cu}, \mathrm{As}$ и $\mathrm{Fe}$ в донных отложениях расчетные концентрации указанных эл- 
Tаблица 3. Расчетные концентрации Fe, $\mathrm{Cu}, \mathrm{Zn}, \mathrm{Pb}, \mathrm{As}$ в речных водах при разных значениях коэффициента водного стока $Q / Q_{a}$, кониентрации исследуемого вещества в донных отложениях $S$, $p$ н речной воды, заболоченности водосбора $f_{\text {sw, }}$, реднемноголетнем модуле водного стока $M_{a Q}$

Table 3. Simulated concentration of $\mathrm{Fe}, \mathrm{Cu}, \mathrm{Zn}, \mathrm{Pb}, \mathrm{As}$ in river waters at different values of water flow factor $\mathrm{Q} / \mathrm{Q}_{a}$, concentration of researched substance in bottom sediments $S, p H$ of river water, marshiness of a river basin $f_{s w}$, mean long-term module of water flow $M_{a Q}$

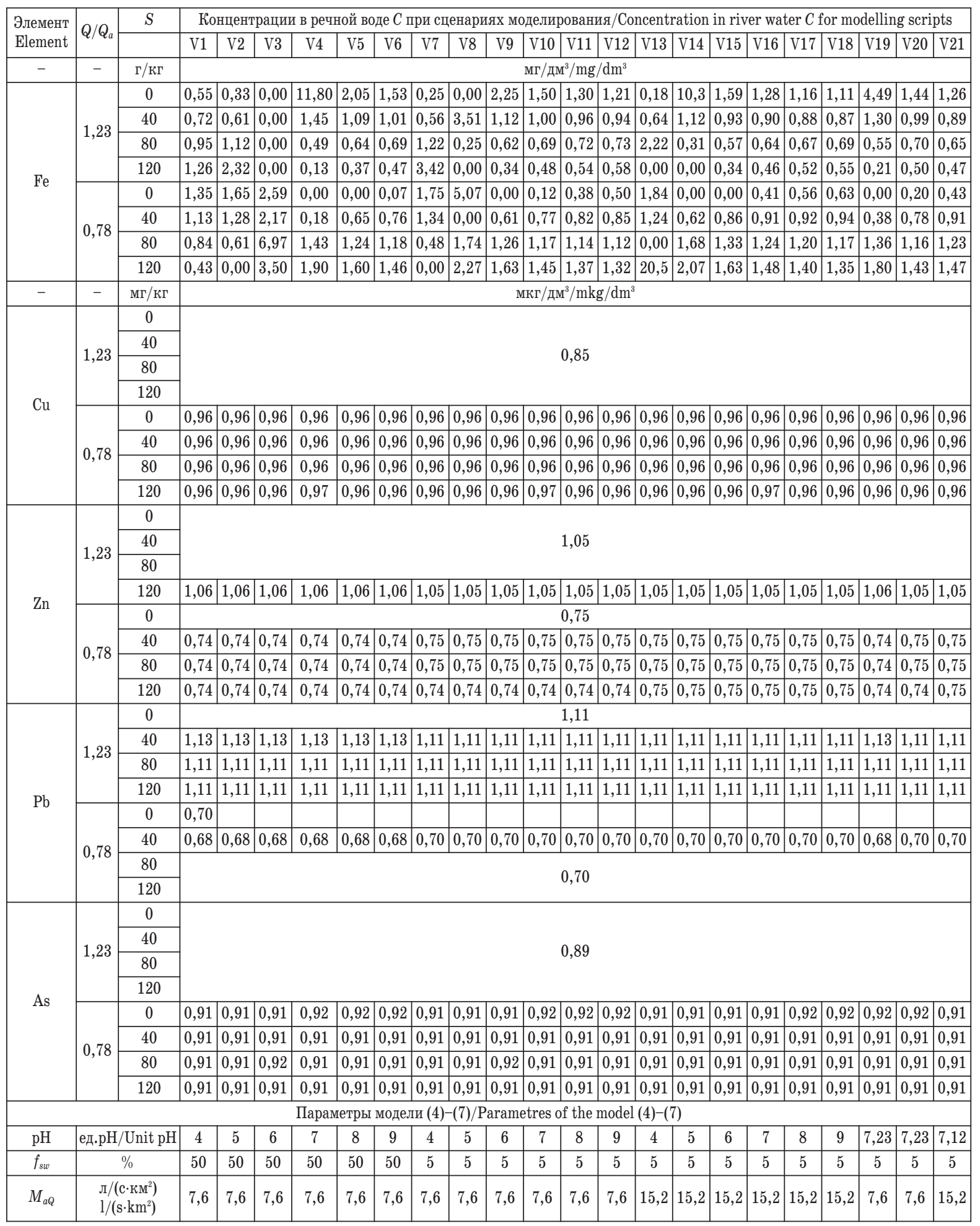


ементов в речных водах возрастают в периоды с пониженной водностью (относительно нормы водного стока) и снижаются в периоды с повышенной водностью (рис. 1), причем возможны такие условия, при которых будут наблюдаться резкие колебания концентраций в речных водах и донных отложениях (рис. 2, 3). Обратная картина характерна для $\mathrm{Zn}$ и $\mathrm{Pb}$ (более высокий уровень содержания возможен при более высокой водности).

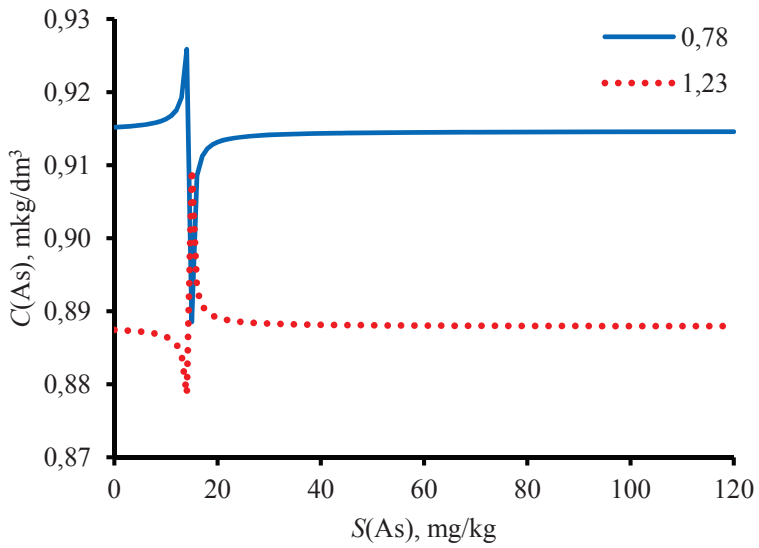

Рис. 3. Расчетные соотношения концентраций As в речных водах (C) и донных отложениях (S) реки с заболоченно стью водосбора $f_{\text {sw }}=5 \%$ и $\mathrm{pH}=7,0$ (сиенарий V10, табл. 3 ) при коэффициенте водного стока $Q / Q_{a} 0,78$ и 1,23

Fig. 3. Simulated ratio of As concentration in waters (C) and bottom sediments ( $S$ ) of the river with basin marshiness $f_{s w}=5 \%$ and $p H=7,0$ (script V10, table 3 ), factor of water flow $Q / Q$ 0,78 and 1,23

Необходимо отметить, что хорошо выраженные изменения концентраций в зависимости от расхода и $\mathrm{pH}$ речных вод, а также заболоченности водосбора характерны, прежде всего, для железа. Концентрации $\mathrm{Cu}, \mathrm{Zn}, \mathrm{Pb}, \mathrm{As}$ изменяются в более узком диапазоне (табл. 3). Это, с одной стороны, внушает некоторый пессимизм с точки зрения использования гидрогеохимических данных для поисков полезных ископаемых ввиду сложности и неоднозначности связей $S$ и $C$. Использование последних, конечно же, возможно, но более эффективно в комплексе с литогеохимическими работами. При этом плотность опробования может корректироваться с учетом региональных зависимостей концентраций веществ в донных отложениях от соотношения площади водосбора и его бессточной части в истоках рек, а также сопряженности речной сети и тектонических нарушений [38]. Собственно гидрогеохимическое опробование наиболее целесообразно проводить в летне-осеннюю межень, когда наблюдается пониженный водный и твердый сток. Но даже выявленные высокие концентрации веществ в речных водах, сами по себе, не свидетельствуют о наличии природной или антропогенной геохимической аномалии в донных отложениях (рис. 2,3 ), что необходимо учитывать при интерпретации результатов поисков и экологического мониторинга.

C другой стороны, результаты моделирования весьма оптимистичны в части оценки антропоген- ных воздействий на водные объекты - абсолютное и относительное приращение концентраций веществ в речных водах обычно заметно меньше соответствующего приращения в донных отложениях. Безусловно, переход вещества из донных отложений в водный поток возможен, особенно при поддержании кислой и слабокислой среды [39]. В том числе вероятно и вторичное загрязнение речных вод. Но последнее в сочетании с прямым воздействием (перенос твердых частиц), как было показано в [40], обычно локализовано на участках до 4-5 км от источника загрязнения (максимально - 11-12 км).

Анализ результатов моделирования также позволяет, вслед за С.Л. Шварцевым [2, 41], предположить, что для формирования высоких содержаний некоторых химических элементов в поверхностных и подземных водных объектах достаточно определенного сочетания природных условий, определяющих преобладание аккумуляции над выносом даже при отсутствии крупных эндогенных источников. В случае железа к ним могут быть отнесены: 1) высокая заболоченность водосборной территории, определяющая повышенную максимальную сорбционную способность грунтов; 2) общее долгосрочное снижение интенсивности водообмена (в том числе, и за счет ухудшения дренированности территории), не нарушаемая резкими колебаниями водного стока. Такие условия, например, могли наблюдаться с конца мезозоя на территории современного Бакчарского района Томской области, где выявлены проявления осадочных железных руд $[9,42]$.

\section{Заключение}

В результате исследования получены следующие результаты:

1) разработана и апробирована математическая модель взаимосвязей между концентрациями $\mathrm{Fe}, \mathrm{Cu}, \mathrm{Zn}, \mathrm{Pb}, \mathrm{As}$ в речных водах и донных отложениях в условиях таежной зоны и горно-таежных районов Сибири, предложен алгоритм определения параметров этой модели;

2) связи между химическим составом речных вод и донных отложений существенно нелинейны и зависят от абсолютных и относительных характеристик интенсивности водообмена, заболоченности водосборных территорий и $\mathrm{pH}$ речных вод;

3) абсолютное и относительное приращение концентраций в речных водах обычно меньше, чем соответствующее приращение концентраций в донных отложениях, что в целом обеспечивает устойчивость химического состава речных вод при малых и средних антропогенных нагрузках на водные объекты (под такой нагрузкой нами понимается воздействие в пределах ошибки определения и геохимического фона, соответственно);

4) высокие концентрации Fе и некоторых микроэлементов ( $\mathrm{Pb}, \mathrm{As})$ и их резкие колебания в речных водах в ряде случаев могут быть связаны не только с наличием природных геохимиче- 
ских аномалий в донных отложениях или загрязнением водного объекта, но и с определенными сочетаниями природных условий, например, с приближением фактической сорбции к максимально возможным значениям;

5) влияние процессов растворения-осаждения оказывает не только прямое воздействие на

\section{СПИСОК ЛИТЕРАТУРЫ}

1. Meybeck M. Global chemical weathering of surficial rocks estimated from river dissolved loads // American Journal of Science. 1987. - V. 287. - P. 401-428.

2. Shvartsev S.L. Geochemistry of fresh Groundwater in the Main Landscape Zones of the Earth // Geochemistry International. 2008. - V. 46. - № 13. - P. 1285-1398.

3. Поликарпочкин В.В. Вторичные ореолы и потоки рассеяния. Новосибирск: Наука, 1976. - 407 с.

4. Янин Е.П. Техногенные речные илы (условия формирования, вещественный состав, геохимические особенности). - М.: APCO, 2018. - 415 c.

5. Домаренко В.А. Рациональная методика поисков и геологоэкономической оценки месторождений руд редких и радиоактивных элементов. Ч. 1. Прогнозирование, поиски и оценка. Томск: Изд-во Томск. политехн. ун-та, 2012. - 167 с.

6. Loucks D.P., Van Beek E. Water resources systems planning and management. An Introduction to Methods, Models and Applications. - Turin: UNESCO Publishing, printed by Ages Arti Grafiche, 2005. $-679 \mathrm{p}$.

7. Benedini M., Tsakiris G. Water Quality Modelling for Rivers and Streams. - Dordrecht: Springer, 2013. - 288 p.

8. Методика разработки нормативов допустимых сбросов веществ и микроорганизмов в водные объекты для водопользователей (с изменениями от 31.07.2018 г.). - М.: МПР России, 2018. -35 c.

9. Недра России. В 2 т. Т. 1. Полезные ископаемые / А.А. Смыслов, Н.В. Межеловский, А.Ф. Морозов, Е.А. Басков, А.И. Бурдэ, К.Б. Ильин, А.В. Козлов, Л.В. Кулачков, В.С. Литвиненко, Ю.В. Лир, Д.В. Рундквист, И.Г. Савина, С.В. Сендек, Л.И. Тихомиров, М.Г. Харламов / под ред. Н.В. Межеловского, А.А. Смыслова. - СПб.; М.: Горный ин-т, Межрегион. центр по геол. Картографии, 2001. - $547 \mathrm{c.}$

10. Циркон-ильменитовые россыпные месторождения как потенциальный источник развития Западно-Сибирского региона / Л.П. Рихванов, С.С. Кропанин, С.А. Бабенко, А.И. Соловьев, В.М. Советов, Т.Ю. Усова, М.А. Полякова / под ред. Е.Н. Трибунского, М.С. Паровинчака. - Кемерово: 000 «Сарс», 2001. $214 \mathrm{c.}$

11. Трансформация минерального состава донных отложений от истоков к устьям рек / О.Г. Савичев, В.А. Домаренко, Е.В. Перегудина, 0.Е. Лепокурова // Известия Томского политехнического университета. Инжиниринг георесурсов. - 2018. T. 329. - № 7. - С. 43-56.

12. Савичев 0.Г., Копылова Ю.Г., Хващевская А.А. Эколого-геохимическое состояние окружающей среды в Северном Приангарье (Восточная Сибирь) // Известия Томского политехнического университета. - 2010. - Т. 316. - № 1. - С. 129-136.

13. Магмо-рудно-метасоматическая система Актуру в Горном Алтае / А.И. Гусев, А.Ф. Коробейников, А.Я. Пшеничкин, В.А. Домаренко // Успехи современного естествознания. 2014. - № 7. - C. 75-79.

14. Транспорт загрязняющих веществ по крупным рекам европейского Севера и Сибири / А.М. Никаноров, В.А. Брызгало, 0.С. Решетняк, М.Ю. Кондакова // Водные ресурсы. - 2015. T. 42. - № 3. - C. 279-287. DOI: 10.7868/S0321059615010101. уровень содержания $\mathrm{Fe}$ и микроэлементов в водах рек Сибири, но и косвенное (возможно, даже более значимое), за счет формирования максимальной сорбционной способности донных отложений.

Работа выполнена при финансовой поддержке гранта РФФИ № 18-55-80015, 17-05-00042.

15. Моисеенко Т.И. Эволюция биогеохимических циклов в современных условиях антропогенных нагрузок: пределы воздействий // Геохимия. - 2017. - № 10. - С. 841-862. DOI: $10.7868 / \mathrm{S} 0016752517100089$.

16. Водный кадастр Российской федерации. Ресурсы поверхностных и подземных вод, их использование и качество. 2017 год. - СПб: Министерство природных ресурсов и экологии российской федерации, Федеральная служба по гидрометеорологии и мониторингу окружающей среды, Федеральное агентство водных ресурсов, федеральное агентство по недропользованию, 2018. - $153 \mathrm{c}$.

17. Grenthe I., Hummel W., Puigdomenech I. Chemical Background for the Modelling of Reactions in Aqueous systems // Modelling in aquatic chemistry / Eds. I. Grenthe, I. Puigdomenech. - Paris, France: Organisation for economic co-operation and development (OECD). Nuclear Energy Agency, 1997. - P. 69-130.

18. Jakob A. Modelling Solute Transport Using the Double Porous Medium Approach // Modelling in aquatic chemistry. - Paris, France: Organisation for economic co-operation and development (OECD). Nuclear Energy Agency, 1997. - P. 525-576.

19. Solubility, Mobility, and Bioaccumulation of Trace Elements: Abiotic Processes in the Rhizosphere / B. Robinson, N. Bolan, S. Mahimairaja, B. Clothier // Trace elements in the environment: biogeochemistry, biotechnology, and bioremediation / Ed. by M.N.V. Prasad, Ravi Naidu, Kenneth S. Sajwan. - New York, USA: Taylor \& Francis Group, 2006. - P. 97-110.

20. Савичев 0.Г., Нгуен В.Л. 0 методике определения фоновых и аномальных значений гидрохимических показателей // Известия Томского политехнического университета. Инжиниринг георесурсов. - 2015. - Т. 326. - № 9. - С. 133-142.

21. Инструкция по геохимическим методам поисков рудных месторождений. - М.: Недра, 1983. - 228 с.

22. Nash J.E., Sutcliffe J.V. River flow forecasting through conceptual models. P. I - A discussion of principles // Journal of Hydrology. - 1970. - № 10 (3). - P. 282-290.

23. Караушев А.В. Теория и методы расчета речных наносов. - Л.: Гидрометеоиздат, 1977. - 272 с.

24. Drever J.I. The geochemistry of natural waters. - Englewood Cliffs: Prentice-Hall, Inc., 1982. -440 p.

25. Лисицын А.П. Маргинальный фильтр океанов // Океанология. - 1994. - Т. 34. - № 5. - С. 735-747.

26. Ephraim J.H., Allard B. Metal Ion Binding by Humic Substances // Modelling in Aquatic Chemistry / Eds. I. Grenthe, I. Puigdomenech. - Paris, France: OECD, Nuclear Energy Agency, 1997. P. 207-244.

27. Крайнов С.Р., Рыженко Б.Н., Швец В.М. Геохимия подземных вод. Теоретические, прикладные и экологические аспекты. М.: Наука, 2004. - 677 с.

28. Савенко А.В. Экспериментальное моделирование иммобилизации тяжелых металлов на карбонатном сорбционно-осадительном геохимическом барьере // Геохимия. - 2016. - № 8. C. $748-760$. DOI: $10.7868 / \mathrm{S} 0016752516060066$.

29. Савенко А.В. Комплексообразовательно-осадительные геохимические барьеры // Доклады Академии наук. - 2017. - Т. 472. № 5. - C. 572-575. DOI: 10.7868/S086956521705022X.

30. Numerical simulations with the P-Hydroslag model to predict phosphorus removal by steel slag filters / D. Claveau-Mallet, 
B. Courcelles, P. Pasquier, Y. Comeau / / Water Research. - 2017. V. 126. - P. 421-432. DOI: 10.1016/j.watres.2017.09.032.

31. Evaluating solubility of $\mathrm{Zn}, \mathrm{Pb}, \mathrm{Cu}$ and $\mathrm{Cd}$ in pyrite cinder using leaching tests and geochemical modelling / Ch. Tiberg, D. Bendz, G. Theorin, D.B. Kleja // Applied Geochemistry. - 2017. V. 85. - P. 106-117. D0I: 10.1016/j.apgeochem.2017.09.007.

32. Coupled modeling of biospheric and chemical weathering processes at the continental scale / C. Roelandt, Y. Goddéris, M.-P. Bonnet, F. Sondag // Global Biogeochemical Cycles. - 2010. V. 24. - № 2. - P. 6357-6374. DOI: 10.1029/2008GB003420.

33. Савенко В.С. Полуэмпирическая математическая модель вторичного загрязнения водоемов растворенными формами железа и марганца // Водные ресурсы. - 2016. - Т. 43. - № 6. C. $608-619$. DOI: $10.7868 / \mathrm{S} 0321059616060067$.

34. Савенко А.В., Савенко В.С. Растворение алюмосиликатов в воде: эффект второй фазы // Геологическая эволюция взаимодействия воды с горными породами: материалы третьей Всерос. конф. с междунар. участием / Отв. ред. Л.В. Замана, С.Л. Шварцев. - Чита, 20-25 августа 2018 г. - Улан-Удэ: Изд-во БНЦ CO PAH, 2018. - C. 161-164. DOI: 10.31554/978-5-7925-0536-0-2018-161-164.

35. White Ar.F. Chemical weathering rates of silicate minerals in soils // Reviews in Mineralogy. Chemical Weathering Rates of Silicate Minerals. - 1995. - V. 31. - P. 405-462.

36. Савенко А.В., Савенко В.С. Поглощенный комплекс твердых веществ речного стока и его роль в геохимическом балансе океана // Литология и полезные ископаемые. - 2016. - № 1. C. 16-41. DOI: 10.7868/S0024497X16010055.

37. Pokrovsky 0.S., Karlsson J., Giesle R. Freeze-thaw cycles of Arctic thaw ponds remove colloidal metals and generate low-molecu- lar-weight organic matter // Biogeochemistry. - 2018. V. 137. - P. 321-336. DOI: 10.1007/s10533-018-0421-6.

38. Improved method for hydrochemical exploration of mineral resources / Nguyen Van Luyen, 0.G. Savichev, V.A. Domarenko, Quach Duc Tin // Vietnam Journal of Earth Sciences. - 2017. № 39 (2). - P. 167-180. DOI: 10.15625/0866-7187/39/2/9703.

39. Frye E., Bao Chen, Li Li, and Blumsack S. Environmental Controls of Cadmium Desorption during $\mathrm{CO}_{2}$ Leakage // Environmental Science \& Technology. - 2012. - V. 46. - P. 4388-4395. DOI: $10.1021 / \mathrm{es} 3005199$.

40. Нгуен Ван Луен. Эколого-геохимическое состояние подземных и речных вод, донных отложений водотоков в северной части Вьетнама (на примере уезда Чодонь, провинция Баккан): автореф. дис. ... канд. геол.-минерал. наук. - Томск, 2017. - 22 с.

41. Геологическая эволюция и самоорганизация системы вода порода: в 5 т. Т. 2. Система вода-порода в условиях зоны гипергенеза / С.Л. Шварцев, Б.Н. Рыженко, В.А. Алексеев, Е.М. Дутова, И.А. Кондратьева, Ю.Г. Копылова, О.Е. Лепокурова / отв. ред. Б.Н. Рыженко. - Новосибирск: СО РАН, 2007. - 389 c.

42. Ferrimagnetic iron sulfide formation and methane venting across the paleocene-eocene thermal maximum in shallow marine sediments, ancient West Siberian sea / M. Rudmin, A. Mazurov, 0. Savinova, A. Ruban, R. Kashapov, A.P. Roberts, C.-S. Horng, M. Veklich // Geochemistry, Geophysics, Geosystems. - 2018. V. 19. - № 1. - P. 21-42. DOI: 10.1002/2017GC007208.

Поступила 19.02.2019 2.

\section{Информация об авторах}

Савичев О.Г., доктор географических наук, профессор отделения геологии Инженерной школы природных ресурсов Национального исследовательского Томского политехнического университета. 


\title{
RESEARCH OF INTERRELATIONS BETWEEN CHEMICAL COMPOSITION OF WATERS AND BOTTOM SEDIMENTS OF SIBERIAN RIVERS
}

\author{
Oleg G. Savichev, \\ OSavichev@mail.ru \\ National Research Tomsk Polytechnic University, \\ 30, Lenin avenue, Tomsk, 634050, Russia.
}

Relevance. Understanding of the mechanism and quantitative estimation of interaction between river waters and bottom sediments substance is a methodological basis of water restoration planning, ecological monitoring and ores hydrogeochemical searches. The aim of the research is the quantitative description of interrelation between the chemical composition of river waters and bottom sediments.

Methods: statistical methods, mathematical modelling of hydrogeochemical processes.

Results and conclusions. The author has considered the mathematical model of $\mathrm{Fe}, \mathrm{Cu}, \mathrm{Pb}, \mathrm{Zn}$, As interrelations in waters and bottom sediments of some Siberian rivers (the Omutnaya, Ilbokich, Botkich, Top Nemba, Bottom Nemba, Inganba and Aktru rivers; the Omutnaya river in river system Omutnaya-Kirgizka-Tom-Ob rivers; the Ilbokich, Botkich, Top Nemba, Bottom Nemba, Inganba rivers are tributaries of the Chadobets river, system Chadobets-Angara-Yenisei rivers; the Aktru river in system Aktru-Chuya-Katun-Ob rivers). The algorithm of model parameters definition including the regression analysis and optimization methods is proposed. The relations between a chemical composition of river waters and bottom sediments are not linear and depend on absolute and relative characteristics of water exchange intensity, basin marshiness and pH of river waters. The absolute and relative increment of concentration in river waters is usually less than a corresponding increment of concentration in bottom sediments. At the same time, the observed high concentration of Fe and the raised contents of some microelements can be related not only to the natural geochemical anomalies in bottom sediments or water pollution, but also to certain combinations of environmental conditions, for example, to the minimal difference between maxima possible and actual sorption in bottom sediments.

\section{Key words:}

River bottom sediments, river waters, chemical composition, mathematical model, taiga zone of Siberia.

The research was financially supported by the RFBR grant no. 18-55-80015, 17-05-00042.

\section{REFERENCES}

1. Meybeck M. Global chemical weathering of surficial rocks estimated from river dissolved loads. American Journal of Science, 1987, vol. 287, pp. 401-428.

2. Shvartsev S.L. Geochemistry of fresh Groundwater in the Main Landscape Zones of the Earth. Geochemistry International, 2008, vol. 46, no. 13, pp. 1285-1398.

3. Polikarpochkin V.V. Vtorichnyye oreoly i potoki rasseyaniya [Secondary halos and scattering flows]. Novosibirsk, Nauka Publ., 1976. $407 \mathrm{p}$

4. Yanin E.P. Tekhnogennye rechnye ily (usloviya formirovaniya, veshchestvenny sostav, geokhimicheskie osobennosti) [Technogenic river silts (formation conditions, material composition, geochemical features)]. Moscow, ARS0 Publ., 2018. 415 p.

5. Domarenko V.A. Ratsionalnaya metodika poiskov i geologo-ekonomicheskoy otsenki mestorozhdeniy rud redkikh i radioaktivnykh elementov. Ch. 1. Prognozirovanie, poiski $i$ otsenka [Rational methodology for prospecting and geological and economic assessment of ore deposits of rare and radioactive elements. P. 1. Forecasting, searches and evaluation]. Tomsk, TPU Publ. house, $2012.167 \mathrm{p}$.

6. Loucks D.P., Van Beek E. Water resources systems planning and management. An Introduction to Methods, Models and Applications. Turin, UNESCO Publishing, printed by Ages Arti Grafiche, $2005.679 \mathrm{p}$.

7. Benedini M., Tsakiris G. Water Quality Modelling for Rivers and Streams. Dordrecht, Springer, 2013. 288 p.

8. Metodika razrabotki normativov dopustimykh sbrosov veshchestv $i$ mikroorganizmov $v$ vodnyye obyekty dlya vodopolzovateley [Methodology for developing standards for permissible discharges of substances and microorganisms into water bodies for water users]. 31.07.2018. № 342. Moscow, Ministry of Nature Resources of Russia, 2018. 35 p.
9. Smyslov A.A., Mezhelovskiy N.V., Morozov A.F., Baskov E.A., Burde A.I., Ilin K.B., Kozlov A.V., Kulachkov L.V., Litvinenko V.S., Lir Yu.V., Rundkvist D.V., Savina I.G., Sendek S.V., Tikhomirov L.I., Kharlamov M.G. Nedra Rossii.V 2 t.T.1.Poleznye iskopayemye [The bowels of Russia. In 2 vol. Vol. 1. Minerals]. Eds. N.V. Mezhelovsky, A.A. Smyslov. St-Petersburg, Moscow, Mining Institute, Center for geol. Cartography Publ., 2001. 547 p.

10. Savichev 0.G., Domarenko V.A., Peregudina E.V., Lepokurova $0 . E$. Transformation of mineral composition of river sediments from sources to mouth of rivers. Bulletin of the Tomsk Polytechnic University. Geo Assets Engineering, 2018, vol. 329, no. 7, pp. 43-56. In Rus.

11. Savichev 0.G., Kopylova Yu.G., Khvashchevskaya A.A. Ecological and geochemical state of the environment in Northern Angara (Eastern Siberia). Bulletin of the Tomsk Polytechnic University, 2010, vol. 316, no. 1, pp. 129-136.

12. Rikhvanov L.P., Kropanin S.S., Babenko S.A., Solovyev A.I., Sovetov V.M., Usova T.Yu., Polyakova M.A. Tsirkon-ilmenitovye rossypnye mestorozhdeniya kak potentsialny istochnik razvitiya Zapadno-Sibirskogo regiona [Zirkon-ilmenite placer deposits as a potential source of development of the West Siberian region]. Eds. E.N. Tribunsky, M.S. Parovinchak. Kemerovo, Sars LLC Publ., 2001. 214 p.

13. Gusev A.I., Korobeynikov A.F., Pshenichkin A.Ya., Domarenko V.A. Magmo-ore-metasomatic system of Akturu in the Gorny Altai. Successes of modern natural science, 2014, no. 7, pp. 75-79. In Rus.

14. Nikanorov A.M., Bryzgalo V.A., Reshetnyak O.S., Kondakova M.Yu. Transport of pollutants along the major rivers of the European North and Siberia. Water resources, 2015, vol. 42, no. 3, pp. 279-287. DOI: 10.7868/S0321059615010101. In Rus.

15. Moiseyenko T.I. The evolution of biogeochemical cycles in modern conditions of anthropogenic loads: limits of impacts. Geochemistry, 
2017, no. 10, pp. 841-862. DOI: 10.7868/S0016752517100089. In Rus.

16. Vodnyy kadastr Rossiyskoy federatsii. Resursy poverkhnostnykh $i$ podzemnykh vod, ikh ispolzovaniye i kachestvo. $2017 \mathrm{god}$ [Water cadastre of the Russian Federation. Surface and groundwater resources, their use and quality. 2017]. St-Peteburg, Ministry of Natural Resources and Ecology of the Russian Federation, Federal Service for Hydrometeorology and Environmental Monitoring, Federal Agency for Water Resources, Federal Agency for Subsoil Use, 2018. $153 \mathrm{p}$.

17. Grenthe I., Hummel W., Puigdomenech I. Chemical Background for the Modelling of Reactions in Aqueous systems. Modelling in aquatic chemistry. Eds. I. Grenthe, I. Puigdomenech. Paris, Nuclear energy agency Publ., 1997. pp. 69-130.

18. Jakob A. Modelling Solute Transport Using the Double Porous Medium Approach. Modelling in aquatic chemistry. Eds. I. Grenthe, I. Puigdomenech. Paris, France, Nuclear Energy Agency Publ., 1997. pp. 525-576.

19. Robinson B., Bolan N., Mahimairaja S., Clothier B. Solubility, Mobility, and Bioaccumulation of Trace Elements: Abiotic Processes in the Rhizosphere. Trace elements in the environment: biogeochemistry, biotechnology, and bioremediation. Eds. M.N.V. Prasad, Ravi Naidu, Kenneth S. Sajwan. New York, USA, Taylor \& Francis Group Publ., 2006. pp. 97-110.

20. Savichev 0.G., Nguen V.L. The technique for determining background and extreme values of hydrogeochemical parameters. Bulletin of the Tomsk Polytechnic University. Geo Assets Engineering, 2015, vol. 326, no. 9, pp. 133-142. In Rus.

21. Instruktsiya po geokhimicheskim metodam poiskov rudnykh mestorozhdeniy [The instruction on geochemical methods of searching ore deposits]. Moscow, Nedra Publ., 1983. 228 p.

22. Nash J.E., Sutcliffe J.V. River flow forecasting through conceptual models. P. I - A discussion of principles. Journal of Hydrology, 1970, no. 10 (3), pp. 282-290.

23. Karaushev A.V. Teoriya i metody rascheta rechnykh nanosov [Theory and methods of calculation of river sediments]. Leningrad, Gidrometeoizdat Publ., 1977. 272 p.

24. Drever J.I. The geochemistry of natural waters. Englewood Cliffs, Prentice-Hall, Inc., 1982. 440 p.

25. Lisitsyn A.P. Marginalny filtr okeanov [Marginal oceans filter]. Okeanologiya, 1994, vol. 34, no. 5, pp. 735-747.

26. Ephraim J.H., Allard B. Metal Ion Binding by Humic Substances. Modelling in Aquatic Chemistry. Eds. I. Grenthe, I. Puigdomenech. Paris, France, Nuclear Energy Agency, 1997. pp. 207-244.

27. Kraynov S.R., Ryzhenko B.N., Shvets V.M. Geokhimiya podzemnykh vod: teoreticheskie, prikladnye $i$ ekologicheskie aspekty [Geochemistry of ground waters: theoretical, applied and environmental aspects]. Moscow, Nauka Publ., 2004. 677 p.

28. Savenko A.V. Experimental modeling of heavy metal immobilization on carbonate sorption-precipitation geochemical barrier. Geochemistry, 2016, no. 8, pp. 748-760. DOI: 10.7868/S0016752516060066. In Rus.

29. Savenko A.V. Complex-precipitation geochemical barriers. Reports of the Academy of Sciences, 2017, vol. 472, no. 5, pp. 572-575. DOI: 10.7868/S086956521705022X. In Rus.

30. Claveau-Mallet D., Courcelles B., Pasquier P., Comeau Y. Numerical simulations with the P-Hydroslag model to predict phosphorus removal by steel slag filters. Water Research, 2017, vol. 126, pp. 421-432. DOI: 10.1016/j.watres.2017.09.032.

31. Tiberg Ch., Bendz D., Theorin G., Kleja D.B. Evaluating solubility of $\mathrm{Zn}, \mathrm{Pb}, \mathrm{Cu}$ and $\mathrm{Cd}$ in pyrite cinder using leaching tests and geochemical modelling. Applied Geochemistry, 2017, vol. 85, pp. 106-117. DOI: 10.1016/j.apgeochem.2017.09.007.
32. Roelandt C., Goddéris Y., Bonnet M.-P., Sondag F. Coupled modeling of biospheric and chemical weathering processes at the continental scale. Global Biogeochemical Cycles, 2010, vol. 24, no. 2 , pp. 6357-6374. DOI: 10.1029/2008GB003420.

33. Savenko V.S. Semi-empirical mathematical model of secondary pollution of water bodies with dissolved forms of iron and manganese. Water resources, 2016, vol. 43, no. 6, pp. 608-619. D0I: 10.7868/S0321059616060067. In Rus.

34. Savenko A.V., Savenko V.S. Rastvorenie alyumosilikatov v vode: effekt vtoroy fazy [Dissolution of aluminosilicates in water: the effect of the second phase]. Geologicheskaya evolyutsiya vzaimodeystviya vody s gornymi porodami: materialy tretyey Vserossiyskoy konferentsii s mezhdunarodnym uchastiyem [Geological evolution of the interaction of water with rocks. Proceedings of the Third All-Russian Scientific Conference with international participation]. Eds. L.V. Zamana, S.L. Shvartsev. Ulan-Ude, BNTS SB RAS Publ. house, 2018. pp. 161-164. DOI: $10.31554 / 978-5$ 7925-0536-0-2018-161-164.

35. White Ar.F. Chemical weathering rates of silicate minerals in soils. Reviews in Mineralogy. Chemical Weathering Rates of Silicate Minerals. Mineralogical Society of America, 1995, vol. 31, pp. $405-462$.

36. Savenko A.V., Savenko V.S. Absorbed complex of river suspended substances and its role in the geochemical balance of the ocean. Lithology and minerals, 2016, no. 1, pp. 16-41. DOI: 10.7868/S0024497X16010055. In Rus.

37. Pokrovsky O.S., Karlsson J., Giesle R. Freeze-thaw cycles of Arctic thaw ponds remove colloidal metals and generate low-molecularweight organic matter. Biogeochemistry, 2018, vol. 137, pp. 321-336. DOI: https://doi.org/10.1007/s10533-018-0421-6.

38. Nguyen Van Luyen, Savichev 0.G., Domarenko V.A., Quach Duc Tin. Improved method for hydrochemical exploration of mineral resources. Vietnam Journal of Earth Sciences, 2017, no. 39 (2), pp. 167-180. DOI: 10.15625/0866-7187/39/2/9703.

39. Frye E., Bao Chen, Li Li, and Blumsack S. Environmental Controls of Cadmium Desorption during $\mathrm{CO}_{2}$ Leakage. Environmental Science \& Technology, 2012, vol. 46, pp. 4388-4395. dx.doi.org/10.1021/es3005199.

40. Nguen Van Luen. Ekologo-geokhimicheskoe sostoyanie podzemnykh i rechnykh vod, donnykh otlozheniy vodotokov $v$ severnoy chasti Vetnama (na primere uezda Chodon, provintsiya Bakkan). Aftoreferat Dis. Kand. nauk [Ecological and geochemical condition of ground and river waters, river sediments of the minor rivers in the Northern part of Vietnam (by the example of Chodon district, Baccan province). Cand. Diss. Abstract]. Tomsk, 2017. $22 \mathrm{p}$.

41. Shvartsev S.L., Ryzhenko B.N., Alekseev V.A., Dutova E.M., Kondratieva I.A., Kopylova Yu.G., Lepokurova 0.E. Geologicheskaya evolyutsiya $i$ samoorganizatsiya sistemy voda-poroda [Geological evolution and self-organizing of water-rock system. V. 2. Water-rock system in conditions of a zone of active water exchange]. Ed. by B.N. Ryzhenko. Novosibirsk, Siberian Branch of the Russian Academy of Science Publ. house, 2007. 389 p.

42. Rudmin M., Mazurov A., Savinova 0., Ruban A., Kashapov R., Roberts A.P., Horng C.-S., Veklich M. Ferrimagnetic iron sulfide formation and methane venting across the paleocene-eocene thermal maximum in shallow marine sediments, ancient West Siberian sea. Geochemistry, Geophysics, Geosystems, 2018, vol. 19, no. 1, pp. 21-42. DOI: 10.1002/2017GC007208.

Received: 19 February 2019.

\section{Information about thre authors}

Oleg G. Savichev, Dr. Sc., professor, National Research Tomsk Polytechnic University. 